\title{
Ética, responsabilidad y trabajo colectivo en la investigación narrativa
}

\author{
J. Ignacio Rivas Flores', M. Esther Prados Megías², \\ Analía E. Leite Méndez ${ }^{1}$, Pablo Cortés González ${ }^{1}$, M. \\ Jesús Márquez Garcia', Piedad Calvo León'1, Virginia \\ Martagón Vázquez ${ }^{1}$ y Maia Acuña ${ }^{1}$ \\ ${ }^{1}$ Departamento de Didáctica y Organización Escolar, Universidad de Málaga, España | \\ i_rivas@uma.es | https://orcid.org/0000-0001-5571-2011| aleite@uma.es | \\ https://orcid.org/0000-0001-5064-999X | pcortes@uma.es | https://orcid.org/0000-0002- \\ 9604-044X | mariajesusmarquez@uma.es | https://orcid.org/0000-0002-2220-3795 | \\ piedy@uma.es | https://orcid.org/0000-0002-5704-8617 |vmartagon@gmail.com | \\ https://orcid.org/0000-0003-1603-9906 | maiaacunia@hotmail.com | https://orcid.org/0000- \\ 0001-7954-5430 \\ ${ }^{2}$ Departamento de Educación, Universidad de Almería, España | eprados@ual.es | \\ http://orcid.org/0000-0002-6413-2219.
}

\begin{abstract}
Resumen: El grupo de investigación ProCIE, a lo largo de nuestra actividad investigadora y docente, hemos prestado atención especial a los aspectos personales y subjetivos implicados en las mismas. En este texto, mostramos la dimensión ética de la investigación narrativa y biográfica a partir de nuestra práctica particular. Desde nuestra perspectiva, investigar, al igual que enseñar, supone establecer relaciones personales entre todos los implicados (tanto sean sujetos investigadores como investigados). Este planteamiento tiene varias aristas, atravesadas por cuestiones éticas. Primero, implica entender al otro como sujeto de derechos y, por tanto, nos obliga a establecer condiciones a la investigación para que los garantice. Segundo, accedemos a los sujetos desde el respeto a su conocimiento como verdadero (cuentan sus historias, entendiendo que estas implican una forma de conocer el mundo), por tanto, entendemos que es necesario establecer un marco de relaciones horizontal y dialógico. Tercero, investigar colaborativamente implica asumir responsabilidades en torno a los procesos, las cuales se van resolviendo en un proceso de toma de decisiones reflexivo, contextualizado y situado, que afecta a los sujetos implicados.
\end{abstract}

Palabras Clave: Ética; Trabajo colaborativo; Investigación narrativa; Investigación biográfica; Investigación cualitativa.

\section{Introducción}

Cuando hablamos de investigación narrativa ponemos en evidencia cuestiones relevantes que tienen que ver con los sujetos y las relaciones. Por tanto, la responsabilidad de la investigación y de los investigadores e investigadoras va más allá de los meros resultados. De hecho, desde nuestra acción docente e investigadora estamos configurando y sedimentando nuestro propio lugar en el mundo en la medida que nos entendemos como sujetos históricos. Esto nos sitúa ante dilemas éticos y políticos que, en nuestro caso, nos los planteamos desde una perspectiva democrática y plural, empatizando y actuando en, por y para los contextos y las realidades en los que nos hallamos inmersos.

Estamos atravesados, por tanto, por una concepción y un posicionamiento político y ético a partir de un modo de entender nuestra responsabilidad como actores públicos.

En consecuencia, como efecto de las prácticas investigadoras, deviene una ética de sí, en palabras de Rose (2012), una ética de nuestras esperanzas que se entrelazan con las vidas de los más cercanos.

Lo narrado no puede entenderse de otra manera que no sea a partir de un trabajo colectivo en el que están implicados componentes diversos y complejos, que se inician en la experiencia narrada y que tienen su anclaje en el territorio, en el suelo que pisamos.

Lo dilemático se superpone a lo paradigmático y confronta con lo programático, de tal forma que explícitamente, o no, estamos posicionándonos en cada una de las decisiones que tomamos. 
Sin duda lo deseable es que esta sea una opción consciente fruto de la reflexión crítica y de los proyectos sociales compartidos, en la que se comprometen discursos, cuerpos, intenciones, etc.

La investigación nos desafía a posicionarnos, a buscar sentidos que habiliten formas de entender el mundo, para cambiarlo, para no ser indiferentes a él y a las realidades de los sujetos que lo habitan. Ética, estética y política son parte del conocimiento de las relaciones que componen y descomponen las prácticas investigativas, en definitiva, un constante ejercicio ético sobre nosotros mismos a partir de la mirada y la existencia de los otros y las otras.

Con estas premisas planteamos que la investigación biográfica narrativa, por su propia esencia, en tanto producto y proceso (Clandinin, 2013), utiliza una gran diversidad de herramientas.

Con ellas se trata de abrir procesos de conversación y de diálogo interdisciplinario que vulnera los límites entre modalidades y borra las fronteras entre los medios utilizados, los diferentes instrumentos o las tradiciones culturales.

De este modo, se ofrece el compromiso de abrir caminos de discusión que conducen a la toma de conciencia de la siempre contingente y estructurada construcción del conocimiento desde posiciones hegemónicas.

Nuestra investigación parte de los relatos de los sujetos participantes y se orienta hacia la reflexión sobre los sentidos y significados presentes en los relatos para reconstruir propuestas alternativas desde una perspectiva colaborativa, participativa y democrática.

De este modo, avanza desde la relación que se establece con los sujetos y colectivos con sus intereses particulares, conformando una comunidad de reflexión y, en ocasiones, una comunidad de prácticas en la medida en que participamos en las propuestas de cambio que se ponen sobre la mesa.

Al respecto, todos los participantes, investigadores e investigados, forman parte del proceso aportando desde las posiciones relativas de cada uno. En este sentido, construimos propuestas de cambio y de transformación que parten de los grupos y los colectivos, dando un valor particular a las mismas.

De acuerdo con estos planteamientos, nuestro interés en este capítulo es mostrar la dimensión ética de la investigación narrativa y biográfica a partir de nuestra práctica particular y los modos como se presenta en nuestro trabajo.

Por tanto, pretendemos ofrecer los dilemas con los que nos enfrentamos a lo largo de nuestras investigaciones, como una forma práctica de dialogar sobre este tema. Tradicionalmente, en investigación cualitativa las cuestiones éticas se han resuelto de acuerdo con un protocolo que respondía más a las cuestiones programáticas de la investigación (básicamente procedimentales) que a las de índole relacional y subjetiva, que atienden más a una cuestión dilemática, con un contenido más político y personal.

Entendemos que esto conlleva una mayor exigencia ética ya que compromete no solo el procedimiento sino, fundamentalmente, a los sujetos.

La investigación biográfico-narrativa es particularmente sensible a estos aspectos.

Por ello nos planteamos los siguientes objetivos:

- Exponer a la "comunidad científica" una praxis reflexiva vinculada a la ética del investigador/a.

- Reflexionar acerca de los aspectos éticos y políticos implicados en las dinámicas de la investigación cualitativa y biográfico-narrativa.

- Compartir experiencias de investigación que pongan en juego relaciones alternativas entre los sujetos, a partir de los relatos propios del investigador/a.

- Analizar cómo los relatos nos ponen en posición de comprender las dinámicas sociales, políticas y culturales. 
- Avanzar en la posibilidad de construir procesos colectivos de comprensión de la realidad, desde el diálogo, la interacción y, en su caso, la confrontación de posiciones.

- Valorar el proceso de construcción de las narrativas desde una perspectiva democrática y participativa.

El desarrollo de este planteamiento nos obliga a una estructura peculiar que no responde necesariamente a la presentación de una investigación en particular.

Más bien vamos a mostrar los dilemas que han ido apareciendo en las distintas investigaciones en la voz de los sujetos investigadores, mediante la narración de cómo las han afrontado, y no sabemos si atrevernos a decir que hemos resuelto.

\subsection{Navegando entre mares. Nuestra posición onto-epistemológica para otra ética de la investigación}

Las consecuencias de plantearnos la investigación tal como venimos manifestando son diversas. En definitiva, nos enfrentan con las implicaciones éticas vinculadas a la investigación cualitativa en general que, en el caso de lo biográfico y narrativo, adquieren una relevancia especial ya que se basa en el sistema de relaciones que se establecen entre los sujetos en contextos y territorios determinados.

Las implicaciones éticas que supone esta forma de investigar son importantes, ya que tanto sujetos investigados como investigadores quedan expuestos en tanto que ponen en juego sus vidas, sus trayectorias, sus voces particulares, ... en definitiva, su subjetividad.

Hay una exposición pública de estos factores que puede afectar de una forma u otra a su intimidad, a su imagen pública, a sus responsabilidades, etc. Por tanto, es necesario establecer una serie de precauciones éticas que les mantenga "a salvo" (Montes, Kushner, \& Ocaña, 2020).

Desde esta perspectiva cobran especial relevancia las cuestiones onto-epistemológicas como una forma de comprender la realidad de tipo socio-constructivista junto con una comprensión decolonial (Rivas, 2019) de la investigación, que implica una forma de situarnos ante el mundo diferente. Siguiendo a Cortés (2019), que retoma la perspectiva que el grupo de investigación lleva desarrollando desde sus orígenes, presentamos el cuadro 1 que sintetiza el conjunto de rasgos metodológicos, epistemológicos y ontológicos que han venido fundamentando nuestra acción.

Para cada uno de estos rasgos se muestra su influencia en alguna de las líneas de pensamiento que nos guían, con especial incidencia en los componentes éticos que subyacen. El panorama que se muestra es un puzzle complejo que da idea de la diversidad que caracteriza el pensamiento educativo. 
Cuadro 1. Evolución metodológica, epistemológica y ontológica de la investigación narrativa. Extraído de Cortés (2019).

\begin{tabular}{|c|c|}
\hline $\begin{array}{l}\text { Rasgos Metodológicos, } \\
\text { Epistemológicos y } \\
\text { Ontológicos }\end{array}$ & Influencias investigadoras \\
\hline \multirow{2}{*}{$\begin{array}{l}\text { El valor de la experiencia como } \\
\text { "epistemología de investigación" } \\
\text { (Hernández, 2011). }\end{array}$} & $\begin{array}{l}\text { *Plantea la necesidad de comprender/construir el } \\
\text { conocimiento desde la experiencia vivida. }\end{array}$ \\
\hline & $\begin{array}{l}\text { *Hace de la investigación cualitativa narrativa un } \\
\text { recurso más flexible y ético. }\end{array}$ \\
\hline \multirow{2}{*}{$\begin{array}{l}\text { Verdades complejas y el } \\
\text { lenguaje como inter-discurso } \\
\text { (Lópes, 2011) }\end{array}$} & $\begin{array}{l}\text { *La comprensión del mundo pasa por la del sujeto } \\
\text { en un plano complejo y compartido. }\end{array}$ \\
\hline & $\begin{array}{l}{ }^{*} \text { El sujeto se entiende desde la construcción } \\
\text { colectiva que abarca el contexto a través de la } \\
\text { relación de miradas y discursos. }\end{array}$ \\
\hline \multirow[t]{2}{*}{ 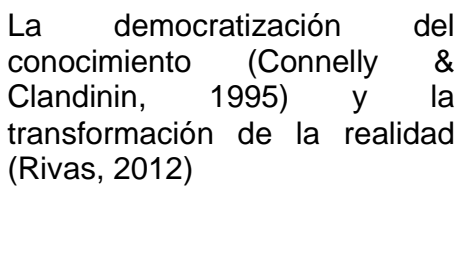 } & $\begin{array}{l}\text { * La investigación narrativa transita hacia un nivel } \\
\text { de complejidad que traslada la autoridad del } \\
\text { conocimiento a los sujetos, por tanto, lo } \\
\text { democratiza. }\end{array}$ \\
\hline & $\begin{array}{l}\text { * Este tránsito genera prácticas transformadoras en } \\
\text { una construcción pública del conocimiento. }\end{array}$ \\
\hline \multirow[t]{4}{*}{$\begin{array}{l}\text { Epistemología crítica de la } \\
\text { complejidad (Kincheloe, 2008) y } \\
\text { la escucha radical (Tobin, 1010) }\end{array}$} & $\begin{array}{l}\text { * Se hacen planteamientos en los que se entienden } \\
\text { los sujetos en constante evolución y en una esfera } \\
\text { de la comprensión compleja. }\end{array}$ \\
\hline & $\begin{array}{l}\text { * Resulta necesario un replanteamiento más allá de } \\
\text { categorías pre-establecidas. }\end{array}$ \\
\hline & $\begin{array}{l}\text { * La escucha radical resulta un acto de consenso en } \\
\text { la forma de entender las diferencias a la hora de } \\
\text { reconfigurar las relaciones humanas. }\end{array}$ \\
\hline & $\begin{array}{l}\text { * La investigación narrativa se entiende desde el } \\
\text { vínculo con el Otro y la Otra. }\end{array}$ \\
\hline
\end{tabular}

Con estas premisas estamos poniendo en juego otra forma de investigar que contemple a los sujetos entrevistados no solo como un factor importante, sino también necesario, en el proceso de investigación. Esto significa una ruptura con la mirada extractiva y expoliadora de la investigación tradicional (también la cualitativa en muchos casos) denunciada desde diversos autores (Santos, 2019; Rivas \& Leite, 2011). En investigación narrativa cobra especial relevancia que la construcción del relato pueda tener una dimensión compartida. Pero aún importa más, si cabe, que haya un proceso colaborativo especialmente en la interpretación, poniendo en evidencia los principios constructivistas manifestados anteriormente, pero también el respeto al conocimiento propio del relato y al sujeto que lo comparte.

Desde un punto de vista ético-político, nos situamos en un contexto deliberativo, en la línea de lo que proponen, entre otros, House y Howe (2001), que apuntan a la necesidad de incorporar modelos políticos democráticos, horizontales y colaborativos, en el contexto de la cotidianidad de la investigación. Tal como señala Kushner (2002), entre otros, las relaciones entre los sujetos tradicionalmente son de tipo jerárquico y de poder, aún en investigaciones de corte cualitativo. Los investigadores suelen hacerse cargo de los datos, cosificando a los sujetos y dejándoles fuera del análisis de sus propias vidas (Corona, Berkin, \& Kaltmeier, 2012). La perspectiva democrática-deliberativa que defendemos permite una construcción intersubjetiva entre todos los sujetos implicados, permitiendo relaciones más horizontales a partir de un respeto profundo por el otro -sujeto investigadocomo portador de conocimiento y soberano del mismo y de su vida. 
Entendemos que forma parte de la ética investigadora reflexionar acerca de las relaciones de poder que se generan en el ámbito de las investigaciones, las cuales siempre existen, incluso encubiertas bajo las fuerzas colonizadoras y opresivas a las que se enfrentan muchas investigaciones de corte cualitativo y narrativo (Denzin, 2017). En este sentido, aspectos como el género, la clase social, la orientación sexual, la raza, la nacionalidad, la posición, los intereses del investigador/a, entre otros aspectos, son elementos a considerar a lo largo de todo el proceso investigador.

\section{La investigación / método / el proyecto}

El objetivo de este capítulo, como ya hemos planteado, no es mostrar un proyecto de investigación específico, sino poner en cuestión la perspectiva ética-política a partir de la praxis de algunas de las investigaciones que el grupo ProCIE ha desarrollado en los últimos años, tanto en forma conjunta como en los proyectos individuales de tesis doctorales. Queremos mostrar, por tanto, qué cuestiones críticas nos han surgido y cómo nos las hemos planteado los propios investigadores, permitiendo así, compartir nuestra experiencia y nuestra reflexión. Presentamos a modo de relatos, cinco reflexiones de los investigadores/as del grupo ProCIE, contextualizadas en el marco de diferentes investigaciones del grupo y del desarrollo de tesis doctorales, donde a partir de sus lecturas convergemos en los dilemas que queremos presentar a la comunidad científica que investiga desde un punto de vista narrativo.

Algunas de estas cuestiones que sometemos a debate público serían:

- Cómo comprendemos al sujeto, así como los procesos de subjetivación y de construcción de la identidad. Investigar nos enfrenta a la necesidad de entender cómo nos constituimos frente al mundo y con los otros y otras. En definitiva, cuestionamos las epistemologías hegemónicas en la investigación, incluso las cualitativas de corte convencional, poniendo sobre la mesa la necesidad de pensarlas en términos de transformación centrada en los valores antropológicos esenciales: la vida, la solidaridad, la justicia, la equidad, la emancipación...

- Qué metodologías son más pertinentes para apoyar los procesos de cambio y transformación social. Entendiendo, como venimos diciendo, que investigar supone una práctica social y política, el modo cómo investigamos es una forma de construir relaciones y, también, de construir sociedad. Forma también es contenido, por lo que no podemos obviar la reflexión sobre los procedimientos en tanto que representan una forma de entender el conocimiento, las relaciones, la sociedad, la educación, etc. Hablamos, así pues, de horizontalidad como una forma de construir relaciones democráticas; de comunidad como un modo de entender lo colectivo; igualmente entendemos la investigación como una forma de resistencia política.

- Cómo consideramos los datos y la información de los sujetos. La propia idea de dato, como producto objetivable de la investigación, puede ser cuestionado desde una perspectiva crítica. Planteamos la necesidad de buscar formas alternativas que no supongan la visión fragmentaria que nos ofrece este término. El relato como unidad, el dilema como percepción del sentido, por ejemplo, pueden suponer formas alternativas de plantear este tema.

- Desde este punto de vista resulta relevante cuestionarnos la relación entre autoría, autorizantes y autorizados, en la dinámica investigadora. Qué voces se hacen públicas; qué tipo de diálogo se establece entre ambas; se puede pensar en una construcción conjunta del relato que dé valor a todas las voces implicadas. 


\subsection{Con voz propia. Algunos relatos acerca de la ética en la investigación.}

\section{Virginia}

Desde el inicio de la investigación, al realizar el proyecto de tesis y plantear establecer contacto con la persona que iba a participar como protagonista de esta, surgieron una serie de incertidumbres relacionadas con la manera de abordar la temática; mi posición en los distintos espacios que íbamos a compartir, tanto en el conversar como a la hora de observar su actividad en el centro, el vínculo que compartía con la maestra, así como la influencia que este podría tener a la hora de realizar el análisis e interpretación de la información recogida en cada uno de los encuentros.

A partir de las primeras conversaciones, me hice consciente de la necesidad de dejar de centrarme en buscar las respuestas a mis inquietudes iniciales (relacionadas con el foco de la investigación) para permitir que ella desarrollara la temática de una forma más espontánea y natural, lo que me permitiría contextualizar los aspectos que fueron emergiendo de ese compartir con ella.

La preocupación por delimitar mis interpretaciones (al haber establecido una relación personal previa al inicio de la investigación) y saber qué parte pertenece a la realidad que ella me está mostrando, se mantiene durante todo el tiempo de recogida y análisis de la información.

Tal y como acordamos antes de empezar la investigación, cada vez que teníamos programado un nuevo encuentro, hacíamos un pequeño repaso sobre lo que habíamos estado compartiendo la vez anterior, lo que me permitía ofrecer un avance sobre las ideas y conceptos que, tras la transcripción y lectura de la información que había recogido, iban apareciendo en el relato. Que ella se reconociera en el relato se estableció como elemento indispensable para iniciar el análisis de este.

Al intentar comprender la realidad que me está compartiendo, me doy cuenta de que la mía está siendo modificada en la interacción. Ella se expone como protagonista y el intercambio a través del diálogo que aparece entre nosotras, provoca en mí un cambio como investigadora.

\section{Pablo}

Entiendo que hablar de ética en la investigación narrativa, se vuelve un elemento crucial y neurálgico que, por un lado, hace posible la gestación de este tipo de investigación y, por otro lado, sirve de guía en la que el proceso importa más que el resultado. Sobre esto último, en otras palabras, resulta de mayor importancia atender a las necesidades, voces, inquietudes, demandas, fricciones y acercamientos con los sujetos participantes en las investigaciones narrativas que simplemente el deseo de rescatar información para concluir un proceso investigador. Aún así tengo varios dilemas que me han interpelado en las distintas investigaciones narrativas en las que he participado.

El primer dilema del que llevo años intentando salir. ¿Acaso los procesos de investigación tienen la misma repercusión en las vidas de quienes la practicamos desde el lado claro de investigadores a quienes se encuadran desde el lado de los participantes? Y más aún en un contexto socio cultural académico en el que el desarrollo profesional depende de los frutos, en formatos académicos, de nuestras investigaciones.

Esto nos lleva adentrarnos en el segundo dilema. Se observa claramente como los tiempos, formatos y lógicas por las que hegemónicamente se impone la ciencia en su producción y auditoría de rendimiento, está, en muchas ocasiones, muy lejos de lo que los procesos de investigación narrativa requieren; llegando al absurdo que muchas revistas llamadas de impacto y foros de difusión científica imponen un formato cerrado, y con tintes paradigmáticos muy claros, de presentación (y por lo tanto, divulgación) de los trabajos académicos y/o científicos. 
El tercer y último dilema, seguro que tengo muchos más, pero sintetizando, tiene que ver con la capacidad de canalizar las potencialidades de la investigación narrativa con las posibilidades de transformación de los contextos socioeducativos. Y más, aún en la era de la conectividad, de la imposición de un formato de relato (a veces desde un relativismo que no deja espacio a la profundidad y crítica del pensamiento, sino a la mera difusión del mismo) y de la emergencia de visibilizar las voces. Tensar entre lo que realmente puede ser transformación a lo que simplemente un recurso más del poder (neoliberal), es realmente un problema o reto al que debemos enfrentarnos y que, por consiguiente, reformula los escenarios que problematizan a la investigación narrativa y que he manifestado anteriormente en forma de dilemas.

\section{Esther}

Pensar éticamente en la investigación biográfica narrativa me hace reflexionar sobre varias cuestiones fundantes que orientan y dan sentido y significado a lo que su propio nombre indica: biografiar. La biografía nos adentra en esos espacios de intimidad, en lugares de individuación, en experiencias en primera persona que dan sentido a la historia de vida o relatos que en estos procesos de investigación se (co)construyen. Por ello, pensar éticamente implica hacerse preguntas, estar atentos al devenir relacional que acontece en este tipo de investigación.

En primer lugar, recuerdo los interrogantes que venían a mi en el proceso de tesis doctoral cuando me disponía a contactar con las personas que iban a participar. Me preguntaba acerca de si elegimos nosotros/as como investigadores/as a las personas o también son ellas las que de algún modo nos eligen a nosotros/as. ¿Qué acontece en este primer paso - elección para que tanto narradores/as como investigadores/as demos nuestro consentimiento a contribuir con la experiencia a estos procesos de indagación y construcción de conocimiento que se produce en la investigación? Quizá ello me hacer reflexionar sobre el sentido y compromiso social y político que las personas tenemos ante el devenir de la sociedad y de la cultura.

El sentido de querer participar en la investigación se deviene una cuestión ética en la medida que la persona que aporta su experiencia en primera persona ya tiene un compromiso ético con su experiencia.

Participar libremente implica ya, desde las personas participantes, un planteamiento ético en cuanto a la toma de decisiones relativas a: visibilización/anonimato, confidencialidad, respeto a la palabra expresada y otras cuestiones emergentes que afloren en el proceso de la investigación. Visibilizar las historias de vida o relatos biográficos tengan o no autoría explícita implica un respeto absoluto a las decisiones que las personas participantes decidan y la consideración de la persona como expresión de lo político, lo cultural y también lo "corpo-emocional".

En segundo lugar, la narrativa ofrece herramientas para considerar el paso de objeto a sujeto-persona. No fue fácil, en mis primeros pasos como investigadora, establecer la distancia "adecuada" que la literatura sobre metodología en investigación cualitativa recomienda para hacer entrevistas, por ejemplo, y mantener una postura objetiva o externa al proceso de escucha.

En narrativa, las relaciones participantes/investigadores-as se tejen en espacios de proximidad, de diálogo, lo cual implica tejer un proceso de conocimiento mutuo, donde el tiempo, los espacios, los detalles, la observación, las palabras, etc., van construyendo un encuentro basado en la escucha y el respeto.

La escucha atenta modifica cualquier planteamiento que, a priori, la investigación puede establecer como propósitos o interrogantes basados en los procesos metodológicos de la investigación. Este planteamiento de estar a la escucha y respetar los procesos de las personas participantes puede modificar los propios "planes" de la investigación estructurados inicialmente. En este sentido, apunto hacia la idea de reflexividad como elemento presente en todo el proceso que cuestiona las propias interpretaciones, la producción de conocimiento y visibiliza los espacios de poder. Mantener un equilibrio entre los diseños de investigación, el rol de la persona investigadora y las decisiones en el 
"campo" de investigación implica interrogarse éticamente sobre estas cuestiones, situando siempre a la persona en el centro de la investigación y no en los intereses del proyecto de investigación.

En tercer lugar (aunque es este aspecto aún la comunidad científica mantiene resistencias) estamos hablando de procesos colectivos, de procesos de diálogo para comprender la cultura -en términos generales-.

De ahí que todo lo relativo a la construcción conjunta requiere de planteamientos éticos donde estemos valorando las coautorías de lo que se genera como conocimiento en la propia investigación, es decir, considerar las producciones narrativas de forma colaborativa implica una forma de mirar a la investigación desde un planteamiento multidimensional, complejo y plural que haga reflexionar críticamente más allá de la comunidad investigadora.

\section{Analía}

La dimensión ética en el trabajo como investigadora siempre constituye un punto de malestar o de inquietud en el sentido de no saber si estoy considerando al otro o a la otra desde lo que el otro quiere hacer y decir, o si por el contrario estoy centrada en los objetivos o finalidad de la investigación a desarrollar.

Creo que las investigaciones, aunque pueden tener unos objetivos generales, se van desarrollando en conjunto, con los demás y no siempre siguen los caminos que una espera; este sería un primer aspecto a tener en cuenta. Otro tiene que ver con el manejo de la información, con la confidencialidad, con el anonimato o no que quieran guardar los sujetos en el trabajo con historias de vida, por ejemplo. Una última cuestión es el tema de la autoría de los trabajos de investigación.

Toda investigación se hace con otros y otras, por lo que las producciones tendrían que ser colectivas y tendríamos que hablar de coautorías. Aquí, muchas veces, no llegamos porque la investigación es pensada desde otro lugar y luego se comparte o contactamos con las personas con las que vamos a investigar y los planteamientos son ajenos, es difícil crear o generar coautorías, pero es una condición necesaria... Esta reflexión ya la escribía en el 2011, a propósito de mi tesis doctoral.

El interrogante planteado nos remite a la dimensión ética de la investigación narrativa biográfica en cuanto a las relaciones que se establecen entre narrador-narratario o investigador-investigado y en cuanto al producto de estas relaciones: la historia de vida reconstruida.

En este sentido, comprender las relaciones desde un plano de cooperación y diálogo provoca un cambio en las relaciones de poder presentes en toda investigación: ¿quién investiga a quien?, ¿qué valor asume el conocimiento del otro cuando los significados del otro son re-significados desde uno mismo? En este juego, emergen nuevos sentidos y posibilidades de comprensión.

Cuando un relato no pertenece ni al narrador ni al narratorio, ninguno posee más conocimiento que el otro, sino que ambos realizan un aporte característico desde su posición, contribuyendo, por una parte, y complementándose.

Los movimientos recíprocos e inversos de uno/a y otro/a permiten la creación de un espacio, de un sistema de comunicación donde una parte de vida encuentra sus conceptos y unos conceptos encuentran vida. En la producción de una historia de vida, el narrador no es el único que habla, piensa y se transforma y esta transformación mutua que se instala desde la reconstrucción de la vida del otro/a supone una mirada sobre la propia vida del investigador/a, que de una u otra manera también se pone en juego. Esta es la dimensión ética de la perspectiva biográfica que me enfrentó con una serie de preocupaciones en cuanto a la fidelidad del relato, a la reconstrucción del trasfondo social y político de las historias de vida y a la tensión de la puesta en juego de diversas lógicas: la lógica de un maestro y una maestra con su experiencia directa en el aula y en los centros educativos y la lógica de los investigadores con sus procesos de abstracción y 
comprensión han requerido una constante y atenta mirada sobre lo hecho y sobre las decisiones que tomé durante todo el proceso de investigación

\section{Nacho}

Una de las primeras preocupaciones que me surgió desde que investigo narrativamente tiene que ver con el lugar del sujeto en la investigación. Acostumbrado, de acuerdo a los estándares de la investigación cualitativa, a manejar la ética de la investigación en términos procedimentales o de protocolos de investigación, preocupados por salvaguardar a este sujeto de una identidad pública, la narrativa me enfrentó justamente a lo contrario. Esto es, si estoy investigando vidas de personas concretas, con identidad propia, qué sentido tiene mantener el anonimato y la confidencialidad como condiciones éticas de la investigación. De hecho, los propios sujetos fueron los que reclamaron, en muchos casos, aparecer públicamente en la investigación. Lo cual me llevó a otras consideraciones que fueron reconfigurando mi perspectiva sobre este tema. De hecho, en el fondo creo que se esconde la pretensión positivista de generar una apariencia de neutralidad y objetividad.

La investigación que desarrollamos pone el peso justo en lo contrario. Entender que cada individuo es portador de conocimiento, que ha sido construido a lo largo de la experiencia en su ciclo de vida, la identidad no queda fuera de esta ecuación. Es más, la investigación narrativa afronta la subjetividad (o la identidad, dependiendo la perspectiva) como el valor central del proceso. Por tanto, que esta sea pública implica dos cosas, por un lado, el reconocimiento a quien ofrece su vida para la investigación y, por otro lado, el carácter situado del conocimiento que se pone en juego.

Esto nos lleva a una cuestión importante que cada día nos lo planteamos con una mayor exigencia: la autoría de una investigación, en términos de producción, publicación, difusión, etc. no es exclusiva de los investigadores. En tanto hablamos de un trabajo cooperativo hay que pensar también en una autoría compartida, por un lado. Igualmente, no podemos segregar a los sujetos investigados de estos productos ya que, si creemos en su soberanía sobre sus relatos de experiencia, esta deberíamos ampliarla a lo que se hace con ellos.

La siguiente cuestión que se nos presenta en la investigación, desde el punto de vista ético - político, es el interés colaborativo (incluso cooperativo) de la investigación. Desde el principio de mi experiencia encontré la exigencia (propia, más que institucional) de implicar a los sujetos investigados en el propio proceso investigador. Analizar privadamente los relatos que se me ofrecían, para hacer mi propia valoración, me hacía sentir como usurpador; como si me estuviera apropiando de algo que no es mío. Este es un planteamiento ético en todos los ámbitos de la vida, que especialmente debería aplicarse al mundo académico. Desgraciadamente la investigación suele jugar en este tablero. Interpretar un relato, requiere el diálogo con quién lo ha escrito. En relación a esto hemos tenido siempre interés en incorporar a los sujetos investigados no solo en la fase interpretativa, sino desde el principio del proceso. Esto no solo ha enriquecido los "resultados", sino que ha generado compromisos distintos en todo el grupo, y una posibilidad real de incidir en la transformación de la realidad.

En este sentido, en último lugar, hemos sentido la necesidad de ir más allá, implicándonos en los contextos de investigación como un requisito ético-político. En el momento actual nuestra investigación se lleva a cabo en escenarios en los que estamos implicados por razones diversas, participando en las dinámicas y procesos que tienen lugar en los mismos. Nuestra investigación tiene sentido, en buena parte, en la medida que estamos dando respuesta a las necesidades e intereses colectivos de estos contextos, y no solo a nuestros intereses académicos - productivos - profesionales...

A continuación, en el siguiente cuadro, reflejamos algunas posibilidades o estrategias que permiten de manera más práxica abordar los aspectos éticos que abordamos en este escrito: 
Cuadro 2. Estrategias práxicas para atender a aspectos éticos en la investigación biográficonarrativa.

\begin{tabular}{|c|c|}
\hline $\begin{array}{l}\text { ELEMENTOS A } \\
\text { CONSIDERAR }\end{array}$ & $\begin{array}{c}\text { RECONSIDERACIONES ÉTICAS, } \\
\text { EPISTEMOLÓGICAS Y } \\
\text { METODOLÓGICAS }\end{array}$ \\
\hline \multirow[t]{2}{*}{$\begin{array}{l}\text { La negociación del } \\
\text { proyecto }\end{array}$} & $\begin{array}{l}\text { * Requiere de procesos de diálogo } \\
\text { activo y son parte principal del } \\
\text { proceso investigador }\end{array}$ \\
\hline & $\begin{array}{l}\text { *os/as participantes incorporan } \\
\text { deseos, pretensiones y límites que } \\
\text { pueden desbordar a lo estrictamente } \\
\text { investigador (por ejemplo, incorporar } \\
\text { procesos de colaboración, } \\
\text { divulgación no científica, etc.) }\end{array}$ \\
\hline \multirow[t]{3}{*}{$\begin{array}{l}\text { Autoría de los } \\
\text { resultados }\end{array}$} & $\begin{array}{l}\text { Los resultados de una investigación } \\
\text { biográfico-narrativa, como se ha } \\
\text { apuntado con anterioridad, pueden } \\
\text { ser muy variados; la autoría se tiende }\end{array}$ \\
\hline & $\begin{array}{l}\text { a que sea compartida con las } \\
\text { personas participantes, al menos } \\
\text { cuando se trabajan relatos o historias } \\
\text { de vida muy personalistas o } \\
\text { pertenecientes a procesos grupales. }\end{array}$ \\
\hline & $\begin{array}{l}\text { En muchos casos, hemos firmado, } \\
\text { incluso, artículos de divulgación } \\
\text { científica con los sujetos } \\
\text { participantes }\end{array}$ \\
\hline $\begin{array}{l}\text { Las voces de los } \\
\text { sujetos participantes }\end{array}$ & $\begin{array}{l}\text { El relato es el que guía el proceso } \\
\text { investigador, lo que se expongan en } \\
\text { los relatos debe tener el sentido que } \\
\text { cada sujeto le otorgue. A lo largo de } \\
\text { todo el proceso aparecerá lo que } \\
\text { estimen oportuno los y las } \\
\text { participantes. Para este fin, } \\
\text { dependiendo del perfil o propia } \\
\text { diversidad de estos, debemos utilizar } \\
\text { recursos y estrategias para que } \\
\text { accedan a sus voces }\end{array}$ \\
\hline $\begin{array}{l}\text { Devolución o } \\
\text { construcción } \\
\text { compartida }\end{array}$ & $\begin{array}{l}\text { Relacionado con el apartado anterior } \\
\text { y en la medida de lo posible, } \\
\text { tratamos de realizar una } \\
\text { construcción compartida de las } \\
\text { informaciones o de los relatos en } \\
\text { lugar de quedarnos sólo en la } \\
\text { devolución de los mismos. }\end{array}$ \\
\hline
\end{tabular}

\section{Conclusiones}

En este texto intentamos ofrecer un marco con algunas cuestiones ontológicas y epistemológicas desde dónde entendemos como grupo de investigadores e investigadoras la investigación biográfica narrativa.

A partir de ello, y teniendo como orientaciones las aportaciones de los propios relatos, aportamos elementos para una reflexión en torno a los ejes que nos problematizan como investigadores e investigadoras en torno a la dimensión ético-política de la práctica en investigación. 
Presentar los relatos como punto de partida lo consideramos una importante praxis en investigación, en la medida que nos confronta continua y colectivamente a las decisiones e interrogantes que este tipo de investigación implica.

La trayectoria del grupo de investigación en el enfoque biográfico narrativo ha permitido poner en cuestión algunos presupuestos éticos convencionales de la investigación cualitativa, considerando que éstos abordan no sólo protocolos consensuados por la comunidad científica sino decisiones y compromisos que llevan a cuestionar los dilemas expuestos en el texto.

En cuanto cuestión ética, implica una dimensión colectiva, en tanto hay un proyecto comunitario que se pone en juego y del que somos parte, de acuerdo a nuestros compromisos públicos. Pero también una dimensión individual en tanto que cada uno de nosotros y nosotras asume una posición particular que pone en juego en su implicación en este proyecto conjunto.

En coherencia con este planteamiento hemos considerado necesario atender a estas voces individuales y su respuesta a estas demandas, vinculadas con aspectos como: la consideración del sujeto como agente de cambio, transformación y conocimiento junto con los investigadores/as; metodologías que promuevan justicia, equidad y procesos de emancipación; producción de dilemas, relatos, reflexiones más allá del puro dato o resultado; autorías compartidas como otra forma de hacer públicas las diferentes voces en la investigación.

Todo ello nos permite, sin duda, avanzar en un diálogo crítico, como única forma de construir un proyecto compartido de transformación social, tanto en los procesos formativos de investigadores/as noveles como con el compromiso que adquirimos desde nuestra posición de profesorado universitario e investigador.

\section{Referencias}

Clandinin, D. (2013). Engaging in narrative inquiry. Walnut Creek, CA: Left Coast Press.

Connelly, F. M., \& Clandinin, D. J. (1995). Relatos de experiencia e investigación narrativa. En J. Larrosa y otros (eds.), Déjame que te cuente. Ensayos sobre narrativa y educación. Barcelona: Laertes.

Corona Berkin, S., \& Kaltmeier, O. (coords.) (2012). En diálogo. Metodologías horizontales en Ciencias Sociales y Culturales. Barcelona: Gedisa

Cortés, P. (2019). Investigación narrativa para la transformación social. Un balance situacional. En M.J. Márquez, P. Cortés, A. Leite \& I. Espinosa (eds.), Narrativas de vida y educación. Diálogos para el cambio social. Barcelona, Octaedro.

Denzin, N. K. (2017). El arte y la práctica de la interpretación, la evaluación y la presentación. Barcelona: Gedisa.

Hernández, F. (2011). Las historias de vida en el marco del giro narrativo en la investigación en Ciencias Sociales: Ios desafíos de poner biografías en contexto. En F. Hernández, J.M. Sancho \& J.I. Rivas (coords.). Historias de Vida en Educación. Biografías en contexto (pp. 13-22). Universitat de Barcelona: Esbrina-Recerca. http://hdl.handle.net/2445/15323

House, E.R., \& Howe, K.R. (2001). Valores en evaluación e investigación social. Madrid: Morata

Kincheloe, J. (2008). Knowledge and critical pedagogy. An introduction. Montreal: Springer.

Lópes, A. (2011). Las historias de vida en la formación docente: orígenes y niveles de la construcción de identidad de los profesores. En F. Hernández, J.M. Sancho, \& J.I. Rivas (Coords.), Historias de vida en educación. Biografías en contexto (pp. 23-33). Barcelona: Esbrina Recerca.

Montes, R., Kushner, S., \& Ocaña, A. (2020). Investigación ética en tiempos de algoritmos y big data. En J.M. Sancho, F. Hernández, L. Montero, J. de Pablos, J.I. Rivas \& A. Ocaña (eds.), Caminos y derivas para otra investigación educativa y social. Barcelona: Octaedro. 
Rivas, J.I. (2012). Sujeto - Diálogo - Experiencia: El compromiso del encuentro. En J.I. Rivas, F. Hernández, J.M. Sancho \& C. Núñez. (Coords). Historias de vida en educación: Sujeto, Diálogo, Experiencia. Barcelona: Dipòsit Digital UB. http://hdl.handle.net/2445/32345

Rivas, J.I. \& Leite, A.E. (2011). La devolución en los procesos de construcción de los relatos. En F. Hernández, J.M. Sancho \& J.I. Rivas (eds.), Historias de vida en educación. Biografías en contexto. Barcelona: Universitat de Barcelona. Licencia de Creative Commons. http://hdl.handle.net/2445/15323

Rose, N. (2012) Políticas de la vida. Biomedicina, poder y subjetividad en el siglo XXI. Buenos Aires, Argentina: UNIPE. Editorial universitaria.

Tobin, K. (2010). Tuning into others' voices: Beyond the hegemony of mono-logical narratives. In W.M. Roth (Ed.), Re/structuring science education, pp. 13-29. New York, Springer.

\section{Notas biográficas}

José Ignacio Rivas Flores. Doctor en Ciencias de la Educación, Universidad de Málaga y licenciado en Ciencias de la Educación, Universidad Complutense de Madrid. Catedrático del Departamento de Didáctica y Organización Escolar de la Facultad de Ciencias de la Educación de la Universidad de Málaga. Coordinador del grupo de investigación ProCIE (profesorado, comunicación e investigación educativa). Sus líneas de investigación: etnografía educativa e investigación biográfica y narrativa. Sus preocupaciones se centran en la experiencia escolar, la organización de centros educativos, la política educativa y el desarrollo profesional docente. Ha dirigido y participado en proyectos de investigación en España, Argentina y México.

María Jesús Márquez García. Doctora en Educación por la Universidad de Almería y licenciada en Psicopedagogía por la misma Universidad. Actualmente es profesora Ayudante Doctora en el Departamento de Didáctica y Organización Escolar en la Universidad de Málaga, habiendo ejercido también en el Departamento de Educación de la Universidad de Almería, en el que también ha sido becaria de investigación, y en la Universidad de Valladolid (sede Soria). Ha trabajado en el Secretariado Gitano de Andalucía llevando la coordinación de la formación para toda la comunidad. Es miembro del grupo de investigación ProCIE.

Analía E. Leite Méndez. Doctora en Ciencias de la Educación por la Universidad de Málaga y Licenciada en Ciencias de la Educación por la Universidad Nacional del Nordeste, Argentina. Profesora Titular del Departamento de Didáctica y Organización Escolar de la Facultad de Ciencias de la educación de la Universidad de Málaga. Anteriormente profesora de la Facultad de Humanidades de la Universidad Nacional del Nordeste, Argentina. Investigadora e integrante del grupo de investigación ProCIE. Autora de libros y artículos relacionadas con narrativas e identidades docentes, voluntariado, aprendizaje y comunidades de aprendizaje.

Piedad Calvo León. Doctora en Educación por la Universidad de Málaga. Máster Interuniversitario Políticas y Prácticas de Innovación Educativa en la Sociedad del Conocimiento y Máster Coaching. Licenciada en Pedagogía y Diplomada en Magisterio Educación Especial. Actualmente es Profesora en el Departamento de Didáctica y Organización Escolar, Facultad Ciencias de la Educación, Universidad de Málaga. Anteriormente ha sido coordinadora Pedagógica en Fundación por un Espacio Sin Exclusión. Granja Escuela el Pato. Sus líneas de Investigación: Investigación biográficonarrativa, profesorado, inclusión, ecologías de aprendizaje y políticas educativas. Pertenece al grupo de Investigación ProCIE.

Virginia Martagón Vázquez. Profesora sustituta interina en el Departamento Didáctica y Organización Escolar, en la facultad de Ciencias de la Educación de la Universidad de Málaga. Diplomada de Maestra de Educación Especial. Continúa su formación con un posgrado de Innovación Educativa. Actualmente cursa doctorado en la Universidad de Almería. Sus intereses en investigación están relacionados con la formación inicial y continua de las y los estudiantes de educación, y cómo las experiencias vividas en sus trayectorias educativas influyen en sus creencias sobre el proceso de enseñanza-aprendizaje y en la evolución de su identidad docente.

María Esther Prados Megías. Licenciada en Educación Física. Doctora en Antropología Social y Cultural. Profesora titular Universidad. Departamento de Educación. Área de Didáctica de la Expresión Corporal. Universidad de Almería. Líneas de investigación orientadas desde la investigación narrativa: Pedagogía de lo corporal y lo expresivo en el ámbito educativo y de formación inicial; Corporeidad y Construcción de Identidades; Cultura escolar y Cuerpo; Antropología, Cuerpo y Género. Especialista en técnicas de expresión y conciencia corporal. Profesora del Sistema Consciente para la Técnica del Movimiento 
Pablo Cortés González. Licenciado en Pedagogía, Doctor en Ciencias de la Educación y Profesor Titular del departamento de Didáctica y Organización Escolar de la Universidad de Málaga y miembro del grupo de investigación ProCIE -HUM619- de la Junta de Andalucía. Sus intereses investigadores versan en torno a la justicia social, la innovación educativa, la resiliencia y la investigación biográfico-narrativa, del que tiene más de un centenar de aportaciones en revistas, libros y congresos

Maia Acuña. Licenciada en Ciencias de la Educación y actualmente Doctoranda del programa de "Educación y Comunicación social" de la Universidad de Málaga en cotutela con el Programa de doctorado en ciencias sociales de la Universidad Nacional de Entrerríos en Argentina. Actualmente ejerce de profesora de la Universidad Nacional del Nordeste, Argentina. Su trabajo se orienta en las organizaciones educativas en colectivos indígenas desfavorecidos. 